\title{
Body weight and nutritional changes after reduction pneumoplasty for severe emphysema: A randomized study
}

\author{
Tommaso Claudio Mineo, MD, ${ }^{a}$ Vincenzo Ambrogi, MD, ${ }^{a}$ Eugenio Pompeo, MD, ${ }^{a}$ Patrizio Bollero, MD, \\ Davide Mineo, MD, and Italo Nofroni, MD, ${ }^{\mathrm{b}}$ for the Pulmonary Emphysema Research Group*
}

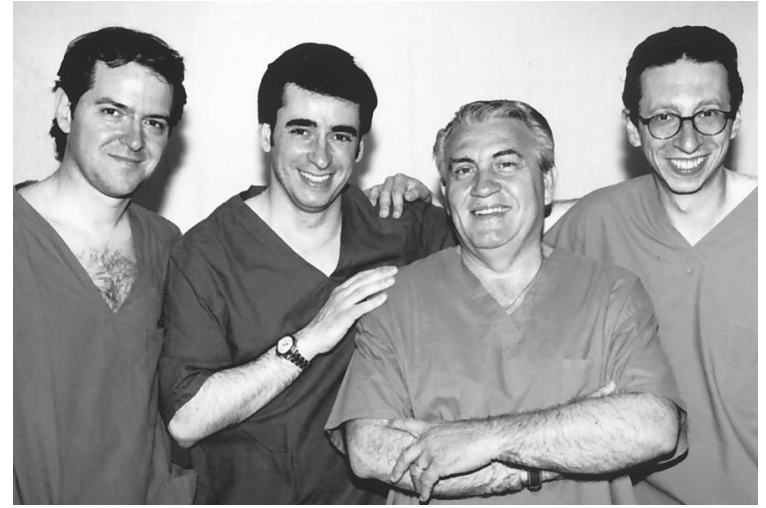

Pompeo, Bollero, Mineo, Ambrogi (left to right)
Background: The impact of reduction pneumoplasty on body weight and nutritional status has not previously been tested in a controlled study.

Methods: We investigated 60 patients with severe emphysema who were randomly assigned to receive either reduction pneumoplasty $(\mathrm{n}=30)$ or a 6 -week respiratory rehabilitation program $(\mathrm{n}=30)$. Nutritional status was evaluated by means of body mass index, triceps skin fold measurement, midarm muscle circumference, and biochemical blood values. Fat mass and fat-free mass were calculated by bioelectric impedance. Two treatment-related deaths occurred after reduction pneumoplasty and 1 death occurred after respiratory rehabilitation.
From the Division of Thoracic Surgery, ${ }^{\mathrm{a}}$ Tor Vergata University, and the Department of Experimental Medicine and Pathology, ${ }^{\mathrm{b}} \mathrm{La}$ Sapienza University, Rome, Italy.

The Pulmonary Emphysema Research Group is supported by grant $9906274194-06$ of Ministero dell’Università e della Ricerca Scientifica e Tecnologica and partially by CNR n. CU0100935CT26 2002.

Received for publication Oct 1, 2001; revisions requested Dec 7, 2001; revisions received Jan 11, 2002; accepted for publication Jan 23, 2002

Address for reprints: Tommaso Claudio Mineo, MD, Cattedra di Chirurgia Toracica, Università Tor Vergata, Policlinico Tor Vergata, Via Oxford, 81, 00133 Rome, Italy (Email:mineo@med.uniroma2.it).

*The members of the Pulmonary Emphysema Research Group are listed in the Appendix.

J Thorac Cardiovasc Surg 2002;124:660-7

Copyright ( $\odot 2002$ by The American Association for Thoracic Surgery

$0022-5223 / 2002 \$ 35.00+0 \quad \mathbf{1 2 / 1 / 1 2 3 8 0 7}$

doi: $10.1067 / \mathrm{mtc} .2002 .123807$
Results: Functional and subjective improvements were significantly showed in reduction pneumoplasty group. Despite insignificant differences in energy intake, the reduction pneumoplasty group showed significant gain $(P<.0001)$ relative to the respiratory rehabilitation group in mean weight changes at 3 months $(1.82 \pm$ $2.63 \mathrm{~kg}$ vs $-0.57 \pm 2.25 \mathrm{~kg}), 6$ months $(2.87 \pm 3.79 \mathrm{~kg} \mathrm{vs}-1.11 \pm 2.64 \mathrm{~kg})$, and 12 months $(3.29 \pm 4.01 \mathrm{~kg}$ vs $-0.95 \pm 1.90 \mathrm{~kg})$. Both fat mass and fat-free mass increased after surgery, but only fat-free mass had a significant improvement $(P=$ .001). Six-month weight gain in the reduction pneumoplasty group was significantly correlated with low baseline weight $(\rho=-0.437, P=.02)$ and residual volume reduction $(\rho=-0.446, P=.01)$. Total proteins $(P=.003)$, albumin $(P=.03)$, transferrin $(P=.04)$, cholesterol $(P=.003)$, hemoglobin $(P=.01)$, triceps skin fold measurement $(P<.0001)$, and midarm muscle circumference $(P<.0001)$ were significantly increased only in the reduction pneumoplasty group. Conversely, in the respiratory rehabilitation group no nutritional index was significantly increased at 6 months after rehabilitation.

Conclusions: Body weight and nutritional status improved only after reduction pneumoplasty and not after respiratory rehabilitation, and this was significantly related to fat-free mass increment. In the reduction pneumoplasty group, the residual volume result was significantly correlated with postoperative weight gain. 


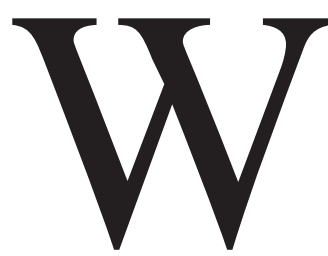

eight loss and malnutrition are widely recognized features of patients with emphysematous chronic obstructive pulmonary disease (COPD). ${ }^{1,2}$ It has been hypothesized that patients with COPD have increases in resting energy expenditure ${ }^{3}$ and in the breathing workload may lead to negative energy balance and weight loss. ${ }^{4}$ On the other hand, Hugli and associates ${ }^{5}$ demonstrated that patients with COPD have normal energy expenditure, despite their increased basal metabolic rate, and hypothesized that these patients spare energy by reducing the physical activity. Furthermore, Baarends and coworkers $^{6}$ showed that daily energy expenditure variations in patients with COPD reflect differences in the activities of the individual patient more than a different basal metabolic rate, and such differences were could be explained by means of decreased respiratory mechanics in COPD.

In recent years reduction pneumoplasty (RP), a palliative surgical procedure that involves resection of $20 \%$ to $30 \%$ of the lung volume, has been demonstrated to improve lung function, exercise capacity, and subjective dyspnea in properly selected patients with COPD. ${ }^{7}$ Body weight has been also reported to improve after $\mathrm{RP},{ }^{8}$ although this effect is inconsistent ${ }^{9}$ and not yet well explained. Even less information is available regarding changes in nutritional status. We hypothesized that RP might improve weight gain and nutritional status and that this effect would probably be due to physiologic improvements induced by the operation itself.

We have already shown in a prospective, randomized, controlled study that sole RP is superior to respiratory rehabilitation (RR) in improving lung function, muscle strength, and exercise capacity. ${ }^{10} \mathrm{We}$ have since studied in the same series of patients the impact of RP relative to maximal medical therapy, including $\mathrm{RR}$, in determining improvements of body weight and nutritional status.

\section{Methods}

\section{Patient Selection}

The study was activated in January 1996 and closed in January 1999. Inclusion criteria were described in a previous report ${ }^{10}$ and are summarized in Table 1. Written informed consent approved by our institution's human research committee was obtained from all patients who took part in this study. Of 237 patients screened, 60 patients entered the study and were randomly divided by the computer into two groups (Figure 1): 30 patients underwent videoassisted thoracoscopic RP and 30 patients underwent a structured, supervised exercise RR program for a minimum of 6 weeks. ${ }^{10}$ No patient in the surgical arm underwent preoperative or postoperative rehabilitation. Among the 125 ineligible patients, 39 had prevailing intrinsic disease of the airway or asthma, 35 did not meet entry spirometric $(n=24)$ or radiologic $(n=11)$ criteria, 22 had clinically significant comorbidities, 14 were still smoking, 8 were had much disability in nutritional status $(n=4)$ or exercise performance $(n=4)$, and 7 were older than 75 years old.

\section{Preoperative Assessment}

Physiologic assessment included measurement of arterial blood gas values, plethysmography, timed spirometry, single-breath diffusing capacity for carbon monoxide, and perfusion scan. Respiratory muscles strength was assessed by means of maximal inspiratory pressure measurement at residual volume (RV) and maximal expiratory pressure at total lung capacity. Digital chest radiographs and high-resolution and volumetric helical computed tomography of the chest were performed in all patients for analysis of emphysema morphologic characteristics and volumes. Exercise tolerance was assessed by standard 6-minute walk test and maximal incremental treadmill test according to a modified Bruce protocol. At baseline and during the follow-up visits, dyspnea was rated according to the modified Medical Research Council score. ${ }^{11}$ Complete symptomatic and functional data collections were repeated 3 and 6 months after completion of treatment. Quality of life was assessed with the 36-item Short Form Health-Related Questionnaire, with the score expressed as a percentage (minimum $0 \%$, maximum $100 \%){ }^{12}$

\section{Nutritional Assessment}

The nutritional assessment included the following: dietary history, physical examination, anthropometric measurements, and biochemical measurements including total protein, albumin, calcium, magnesium, phosphate, hemoglobin, transferrin, and cholesterol blood levels. The dietary history incorporated a 24-hour recall in which the patient described the food eaten during the previous 24 hours or on a typical day, plus a food frequency list. A trained dietician collected the information. On physical examination, typical signs of nutritional deficiency were looked for and noted when present. Anthropometric measures consisted of weight, height, arm circumference, and skin fold thickness determination. Anecdotal reports of weight before development of symptoms were also investigated. Body weight was measured to the nearest $0.1 \mathrm{~kg}$ with a beam scale, and body height was measured to the nearest $0.5 \mathrm{~cm}$ with the patient standing barefoot. The body mass index (BMI, in kilograms per square meter) was then calculated from weight (in kilograms) and height (in meters) as weight/height ${ }^{2}$. Triceps skin fold thickness and midarm muscle circumference (equal to midarm circumference-[triceps skin fold thickness $\times 0.314])$ were assessed by the same skilled dietician according to the standardized techniques. ${ }^{13}$ These measurements were compared with normal values and expressed as predicted percentages obtained with the standard percentiles. ${ }^{14}$ Body composition was measured by 5 -frequency $(1,5,10,50$, and $100 \mathrm{kHz})$ bioelectric impedance analysis (Human IM Scan, Dietosystem; DS Group, Milan, Italy) with the subject in a fasting state, relaxed, and lying in the supine position. Fat mass (FM) and fat-free mass (FFM) were calculated by the conduction of an electric current through the body, according to the software Impedenziometria Plus (version 1.55; DS Group). Body weight, anthropometric measurements, body composition, and nutritional assessment were repeated along with the functional measurements 3 and 6 months after treatment and, when possible, again at 12 months. 
TABLE 1. General entry criteria and indications for unilateral and bilateral RP

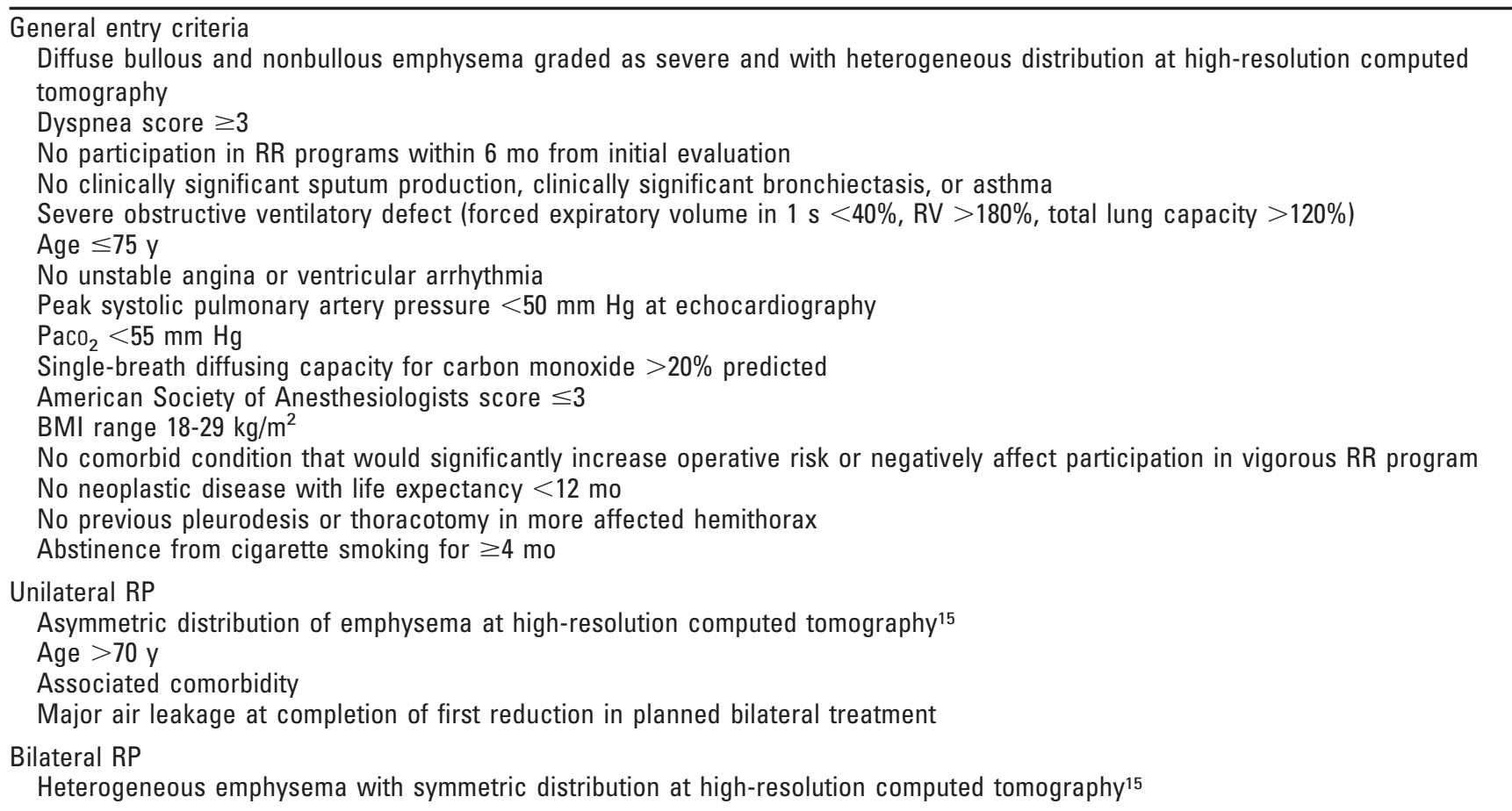

\section{Surgical Technique}

The operation was directed toward reducing $20 \%$ to $30 \%$ of the lung volume by excising functionally useless and hyperinflated lung tissue. Patients assigned to the surgical arm underwent tailored unilateral or bilateral RP. The main indication for unilateral $\mathrm{RP}$ was the finding of an asymmetric distribution of emphysema between the lungs (Table 1). ${ }^{15}$ Staple resection of target areas was routinely performed, excising a single strip of lung tissue. Patients were routinely extubated in the operating room.

\section{Respiratory Rehabilitation}

The outpatient rehabilitation program was directed toward optimizing the ability to perform daily living activities by improving exercise capacity. It entailed 3-hour supervised sessions 5 days per week for at least 6 weeks. The first half of each session included educational activities, such as breathing retraining, chest clearance, energy conservation, nutritional and medication education, and psychosocial support. The second half of each session entailed physical conditioning, including inspiratory resistive exercises, upper extremity training, and lower extremity training.

\section{Study Design and Statistical Methods}

The trial was designed as prospective, randomized, controlled study with transverse and longitudinal evaluations (Figure 1). The transverse evaluation outlined a comparison 6 months after treatment between the patients who had been subjected solely to RP and a control group of patients with homogeneous features who underwent sole RR. Longitudinal evaluation included measurement of the same subject before and 6 months after treatment. Trial duration was set at 6 months on the assumption that for either treatment peak improvements should be reached within the first 6 months. Such a limited duration of the trial was also preferred for ethical purposes, to allow eventual crossover of patients without improvement to the most effective therapy after final follow-up evaluation. Incidental 12-month data were also collected where available, which did not change group. Trial size was considered significant, as noted in a previous report involving the same study population. ${ }^{10}$ Group descriptive statistics were presented as mean \pm SD. Because of the nonnormal distribution of the data and the limited sample size, the Wilcoxon rank-sum test and the Mann-Whitney test were used for paired and unpaired data, respectively.

Changes in oxygen and steroid use were assessed by means of McNemar and $\chi^{2}$ tests as indicated. To determine whether changes in pulmonary function were correlated with weight or nutritional status, we performed the Spearman nonparametric correlation (SPSS 9.05 for Windows, SPSS Inc, Chicago, Ill) of the percentage changes in individual parameters of lung function and percentage changes in body weight and nutritional indices. Data were expressed with the $\rho$ coefficient.

\section{Results}

Results of selected baseline data are summarized in Tables 2 and 3. No differences were found between the medical and surgical arms at study entry in demographic characteristics, BMI, drug treatment, oxygen requirements, pulmonary function, anthropometric measurements, and biologic markers of nutrition (Table 2).

Seventeen patients underwent bilateral RP, whereas 13 


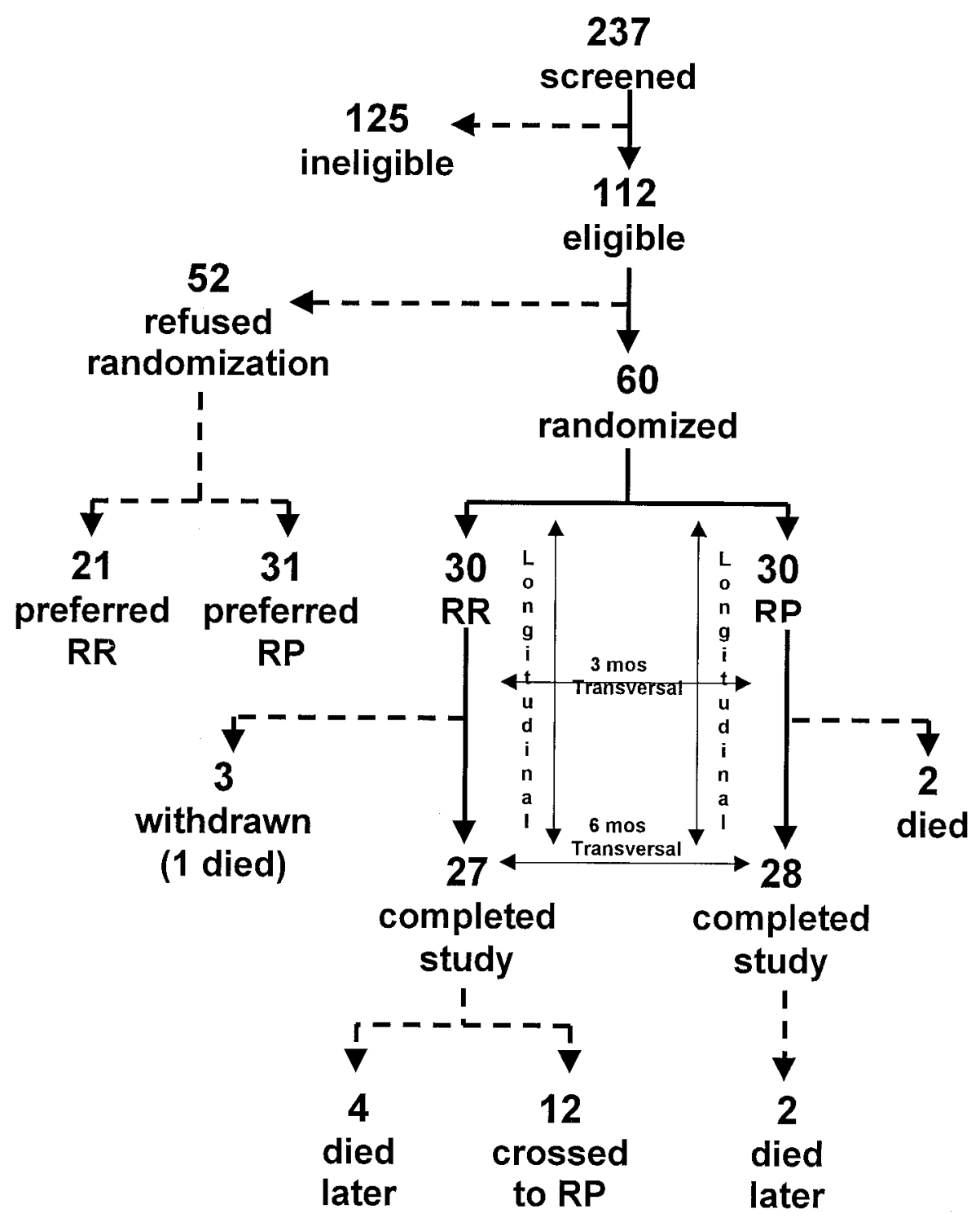

Figure 1. Algorithm showing study subject selection, patient evaluation, treatment plans, and outcome by random assignment.

received unilateral RP. There was no difference between the surgical and medical arms in 6-month mortality (2 vs 1, $P$ not significant). As expected, 1-month morbidity was significantly higher in the surgical arm (16 vs $0, P<.00001)$. Twenty-eight patients from the RP group and 27 from RR group completed the 6-month study (Figure 1). A greater number of patients after RR than after RP had either fatal or nonfatal late complications ( 9 vs $3, P=.03$ ). In the RP arm, 2 patients died at 8 and 23 months of respiratory failure and pulmonary embolism, respectively. In the medical arm, 4 patients died between 7 and 41 months after completion of treatment of respiratory failure $(n=2)$, myocardial infarction $(\mathrm{n}=1)$, and unknown causes $(\mathrm{n}=1)$. Mean follow-up of all recruited patients was $24 \pm 10.4$ months, with 2 patients in the medical arm not available for follow-up. Twelve patients crossed over to surgical treatment because unsatisfactory improvements, thus reducing the number of patients in the RR group available for a follow-up longer than 6 months.

Table 2 illustrates symptomatic, functional, and exercise results observed in the two groups at 6 months. Significant longitudinal improvements were found in both groups, whereas after RR some functional parameters (forced expiratory volume in 1 second, $\mathrm{RV}$, and total lung capacity) did not improve. At the 6-month comparison, the RP group scored significantly better than the RR group in all param- 
TABLE 2. Mean baseline and absolute changes between values before treatment and 6 months after treatment, with intragroup and intergroup significances

\begin{tabular}{|c|c|c|c|c|c|c|c|}
\hline \multirow[b]{2}{*}{ Respiratory function index } & \multicolumn{3}{|c|}{ RP group } & \multicolumn{3}{|c|}{ RR group } & \multirow{2}{*}{$\begin{array}{c}\text { Intergroup } \\
\boldsymbol{P} \text { value }\end{array}$} \\
\hline & Baseline & Change & $P$ value & Baseline & Change & $P$ value & \\
\hline Dyspnea index & $3.3 \pm 0.7$ & -1.52 & $<.0001$ & $3.3 \pm 0.5$ & -0.4 & $<.01$ & $<.0001$ \\
\hline $\begin{array}{l}\text { Forced expiratory volume } \\
\text { in } 1 \mathrm{~s}(\mathrm{~L})\end{array}$ & $0.86 \pm 0.3$ & 0.46 & $<.0001$ & $0.83 \pm 0.2$ & 0.01 & NS & $<.0001$ \\
\hline Forced vital capacity (L) & $2.51 \pm 0.5$ & 0.42 & $<.0002$ & $2.55 \pm 0.4$ & 0 & NS & $<.0001$ \\
\hline RV by plethysmography (L) & $5.5 \pm 0.7$ & -1.4 & $<.0001$ & $5.1 \pm 0.6$ & 0 & NS & $<.0001$ \\
\hline $\begin{array}{l}\text { Total lung capacity by } \\
\text { plethysmography (L) }\end{array}$ & $8.4 \pm 0.8$ & -0.37 & .02 & $8.2 \pm 0.5$ & 0 & NS & $<.001$ \\
\hline $\begin{array}{l}\text { Single-breath diffusing } \\
\text { capacity for carbon } \\
\text { monoxide } \\
(\mathrm{mmol} /[\mathrm{KPa} \cdot \mathrm{min}])\end{array}$ & $2.73 \pm 0.9$ & 0.03 & NS & $2.81 \pm 0.8$ & -0.1 & NS & $<.01$ \\
\hline $\begin{array}{l}\text { Maximal inspiratory } \\
\text { pressure at RV (mm Hg) }\end{array}$ & $50 \pm 14$ & 21 & $<.0001$ & $54 \pm 16$ & 11 & $<.01$ & NS \\
\hline $\begin{array}{l}\text { Maximal expiratory } \\
\text { pressure at total lung } \\
\text { capacity }(\mathrm{mm} \mathrm{Hg})\end{array}$ & $77 \pm 12$ & 5 & NS & $81 \pm 15$ & 2 & NS & NS \\
\hline $\mathrm{PaO}_{2}(\mathrm{~mm} \mathrm{Hg})$ & $68 \pm 7$ & 5 & $<.0001$ & $64 \pm 7$ & 2 & $<.01$ & $<.002$ \\
\hline $\mathrm{PaCO}_{2}(\mathrm{~mm} \mathrm{Hg})$ & $40.5 \pm 4$ & -1.3 & NS & $40.5 \pm 5$ & -0.3 & NS & NS \\
\hline $\begin{array}{l}\text { Quality of life (on } 36 \text {-item } \\
\text { Short Form Health- } \\
\text { Related Questionnaire) }\end{array}$ & $51 \% \pm 12 \%$ & 15.9 & $<.0001$ & $49 \% \pm 16 \%$ & 2.7 & $<.004$ & $<.0001$ \\
\hline 6-min walk test (m) & $380 \pm 43$ & 93 & $<.0001$ & $376 \pm 40$ & 31 & $<.0001$ & $<.0002$ \\
\hline $\begin{array}{l}\text { Incremental treadmill test } \\
\text { (Bruce class) }\end{array}$ & $0.68 \pm 0.5$ & 1.52 & $<.0001$ & $0.83 \pm 0.2$ & 0.48 & $<.0002$ & $<.0001$ \\
\hline $\begin{array}{l}\text { Supplemental oxygen } \\
\text { dependence (No.) }\end{array}$ & 19 & -17 & $<.0001^{*}$ & 18 & -3 & $N S^{*}$ & $<.02 \dagger$ \\
\hline Steroid use* (No.) & 22 & -18 & $<.0001^{*}$ & 24 & -9 & $<.01^{*}$ & NSt \\
\hline
\end{tabular}

All data except numbers of patients are mean \pm SD. NS, Not significant.

${ }^{*}$ By McNemar test.

†By $\chi^{2}$ test.

$\ddagger$ Oral methylprednisolone $(8 \mathrm{mg} / \mathrm{d})$ for at least 1 month.

eters considered except maximal inspiratory pressure at $\mathrm{RV}$, maximal expiratory pressure at total lung capacity, and $\mathrm{PaCO}_{2}$, in all of which statistically nonsignificant improvements were nonetheless recorded.

Despite the lack of significant changes in energy intake, body weight had significantly different trends in the two groups $(P<.0001)$. In the RP group, we found a constant gain relative to baseline values, with changes of $1.82 \pm 2.63$ $\mathrm{kg}$ (range -4 to $6 \mathrm{~kg})$ at 3 months $(P=.004)$ and $2.87 \pm$ $3.76 \mathrm{~kg}$ (range -8 to $9 \mathrm{~kg}$ ) at 6 months $(P=.002)$, with an absolute mean value of $68.4 \pm 9.94 \mathrm{~kg}$. In terms of percentage from baseline, the gain at 6 months was $4.77 \%$. According to the data available from 24 patients at 1 year, mean weight gain was $3.29 \pm 4.01 \mathrm{~kg}$ from the baseline (range -7 to $10 \mathrm{~kg}, P=.002$ ). All but 5 patients gained weight after 12 months. Low body weight was significantly correlated with the percentage of weight gain at 6 months ( $\rho=-0.437, P=.02$ ); the lower the baseline was, the greater was the observed gain. There was no significant difference in 6-month weight gain between patients who underwent unilateral and bilateral RP in either mean values $(2.16 \pm 4.15 \mathrm{~kg}$ vs $3.40 \pm 3.50 \mathrm{~kg}, P=.4)$ or the number of patients who gained weight (8 vs 12).

In the RR group, the patients did not show any weight gain from the preoperative value. Mean weight changes were $-0.57 \pm 2.25 \mathrm{~kg}$ at 3 months and $-1.11 \pm 2.64 \mathrm{~kg}$ at 6 months, with a percentage change of $-1.45 \%$ from the baseline. One-year results were available for 19 patients, and weight change was $-0.95 \pm 1.90 \mathrm{~kg}(-1.39 \%)$.

Variations in BMI followed the same trend as body weight $(-1.45 \%$ of the basal value), with a significant difference between the two groups $(P<.0001)$. There was a correlation between higher percentage of weight gain and lower baseline BMI $(\rho=-0.385, P=.04)$.

Changes in the indices of nutritional status are reported in Table 3. Both FM and FFM increased after surgery, but only FFM had a significant improvement $(P=.001)$. In contrast, after rehabilitation FFM decreased significantly 
TABLE 3. Effect of RP or RR on some nutritional indices with time

\begin{tabular}{|c|c|c|c|c|c|c|c|}
\hline \multirow[b]{2}{*}{ Nutritional index } & \multicolumn{3}{|c|}{ RP group } & \multicolumn{3}{|c|}{ RR group } & \multirow[b]{2}{*}{$\begin{array}{c}\text { Intergroup } \\
\boldsymbol{P} \text { value }\end{array}$} \\
\hline & $\begin{array}{l}\text { Baseline } \\
(n=30)\end{array}$ & $6 \mathrm{mo}(\mathrm{n}=28)$ & $P$ value & $\begin{array}{l}\text { Baseline } \\
(n=30)\end{array}$ & $6 \mathrm{mo}(\mathrm{n}=27)$ & $P$ value & \\
\hline FFM (kg) & $52.6 \pm 7.41$ & $55.4 \pm 6.5$ & .001 & $53.9 \pm 6.4$ & $53.2 \pm 5.3$ & .03 & $<.0001$ \\
\hline FM $(\mathrm{kg})$ & $12.37 \pm 3.73$ & $12.91 \pm 3.83$ & NS & $13 \pm 3.03$ & $13.2 \pm 2.7$ & NS & NS \\
\hline $\begin{array}{l}\text { Midarm muscle } \\
\text { circumference }\end{array}$ & $92.38 \pm 12.09$ & $102.37 \pm 8.88$ & $<.0001$ & $89.53 \pm 9.90$ & $95.03 \pm 6.87$ & NS & .002 \\
\hline $\begin{array}{l}\text { Triceps skin fold } \\
\text { thickness }\end{array}$ & $70.43 \pm 12.80$ & $81.86 \pm 13.67$ & $<.0001$ & $75.38 \pm 11.36$ & $76.34 \pm 12.12$ & NS & .0001 \\
\hline Glucose (mg/dL) & $101.07 \pm 37.3$ & $104.52 \pm 32.5$ & NS & $94.30 \pm 26.7$ & $100.10 \pm 28.7$ & NS & NS \\
\hline $\begin{array}{l}\text { Total proteins } \\
\text { (g/dL) }\end{array}$ & $7.11 \pm 0.59$ & $7.46 \pm 0.65$ & .003 & $7.05 \pm 0.57$ & $7.19 \pm 0.46$ & NS & NS \\
\hline Albumin (g/dL) & $4.02 \pm 0.50$ & $4.19 \pm 0.51$ & .03 & $4.00 \pm 0.40$ & $3.90 \pm 0.39$ & NS & .009 \\
\hline $\begin{array}{l}\text { Transferrin } \\
\text { (mg/dL) }\end{array}$ & $220.83 \pm 77.5$ & $248.15 \pm 72.6$ & .04 & $231.53 \pm 76.3$ & $225.93 \pm 81.4$ & NS & .02 \\
\hline $\begin{array}{l}\text { Hemoglobin } \\
(\mathrm{g} / \mathrm{dL})\end{array}$ & $13.98 \pm 1.24$ & $14.31 \pm 1.07$ & .01 & $14.05 \pm 1.10$ & $13.79 \pm 1.16$ & NS & .02 \\
\hline $\begin{array}{l}\text { Cholesterol } \\
\text { (mg/dL) }\end{array}$ & $154.33 \pm 61.4$ & $175.26 \pm 49.4$ & .003 & $158.90 \pm 59.3$ & $153.15 \pm 47.8$ & NS & .02 \\
\hline $\begin{array}{l}\text { Daily energy } \\
\text { intake (kcal) }\end{array}$ & $1784 \pm 257$ & $1818 \pm 193$ & NS & $1844 \pm 246$ & $1832 \pm 211$ & NS & NS \\
\hline
\end{tabular}

All data are mean \pm SD. NS, Not significant.

$(P=.03)$, whereas FM did not change much. Significant increases were seen at 6 months after the operation in total proteins $(P=.003)$, transferrin $(P=.04)$, cholesterol $(P=$ $.003)$, hemoglobin $(P=.01)$, triceps skin fold thickness $(P<.0001)$, and midarm muscle circumference $(P<$ .0001). In contrast, no significant changes in the variables studied were found in the RR group. Comparison of RP and RR groups showed statistically significant improvements in the RP group in all indices except FM, blood glucose, and total proteins.

In the RP group, there was a significant positive correlation between 6-month weight gain and improvement in RV $(\rho=-0.446, P=.01$; Table 4$)$, whereas no significant correlation was found with forced expiratory volume in 1 second, maximal inspiratory pressure measurement at RV, 6-minute walk test, forced vital capacity, total lung capacity, $\mathrm{PaO}_{2}, \mathrm{PaCO}_{2}$, and incremental treadmill test (data not shown). Correlation with RV was demonstrable for FFM and FM percentage changes (Table 4). No changes in serum biomarkers were significantly correlated with functional tests, subjective tests, and steroid weaning. No correlation between either body weight or nutritional status and functional tests was demonstrable in the RR group.

\section{Discussion}

Our data show that only RP may have a significant impact on increasing body weight for patients with severe emphysema, especially for patients with low baseline weight and BMI. In this subset of patients, weight can return to the status before symptoms. Weight continued to increase even after 6 months, despite increased physical activity and unchanged energy intake among these patients. The main contribution to weight gain was provided by FFM, which was significantly increased after RP and decreased after RR.

In a previous article ${ }^{10}$ on the same patient population, we showed that short-term improvements in dyspnea index, $\mathrm{PaO}_{2}$, inspiratory muscle strength, and exercise capacity occurred after both RP and RR. We also showed that dyspnea index, $\mathrm{PaO}_{2}$, and exercise capacity improved more after RP than after RR, whereas pulmonary function and oxygen requirement improved only after RP. Criner and colleagues ${ }^{16}$ and Geddes and associates ${ }^{17}$ recently demonstrated in two different randomized studies that RP may provide immediate improvement of static volumes and quality of life that is more prolonged than any benefit from maximal medical therapy, including RR. Hypothetic mechanisms of improvement include reduced thoracic hyperinflation and reduced mechanical constraints on lung volume expansion, both of which are related to a reduction in RV. ${ }^{18,19}$ These mechanisms may represent a possible explanation of the greater improvement in symptoms that we have observed after RP, because pulmonary function measures and static lung volumes did not change after RR.

The significant impact of RP on body weight might be explained on the same basis. Low BMI and, indirectly, body weight also proved to be independent predictors of morbidity and mortality after RP for patients with chronic obstructive pulmonary disease and predictors of unfavorable outcome. $^{20}$

The exact mechanism of weight loss in patients with 
TABLE 4. Spearman correlation coefficients for percentage changes in lung function parameters versus percentage changes in body weight and nutritional indices in RP group

\begin{tabular}{|c|c|c|c|c|c|c|}
\hline & $\begin{array}{l}\text { Weight } \\
\text { change }\end{array}$ & FFM change & FM change & $\begin{array}{l}\text { Protein } \\
\text { change }\end{array}$ & $\begin{array}{c}\text { Transferrin } \\
\text { change }\end{array}$ & $\begin{array}{c}\text { Cholesterol } \\
\text { change }\end{array}$ \\
\hline $\begin{array}{l}\text { Forced expiratory } \\
\text { volume in } 1 \mathrm{~s} \\
\text { change }\end{array}$ & NS & NS & $\begin{array}{l}\rho=0.43 \\
P=.02\end{array}$ & NS & NS & NS \\
\hline $\begin{array}{l}\text { RV by plethysmography } \\
\text { change }\end{array}$ & $\begin{array}{l}\rho=-0.45 \\
P=.02\end{array}$ & $\begin{array}{l}\rho=-0.39 \\
P=.04\end{array}$ & $\begin{array}{l}\rho=-0.46 \\
P=.01\end{array}$ & NS & NS & NS \\
\hline 6-min walk test change & NS & NS & NS & NS & NS & NS \\
\hline Quality of life change & NS & NS & NS & NS & NS & NS \\
\hline Steroid weaning & NS & NS & NS & NS & NS & NS \\
\hline
\end{tabular}

NS, Not significant.

emphysema is not known, and there is no general agreement as to whether this is due mainly to FFM depletion. Several hypotheses have been formulated, including chronic inflammation from bronchial infection, loss of muscle strength associated with aging, inactivity, and steroid administration. ${ }^{1,2}$ Creutzberg and colleagues ${ }^{21}$ recently identified a group of patients without response to high-energy nutrition and hypothesized a multifactorial mechanism, including anorexia, shifting in body water compartments, inflammatory mediators, and hypoxia.

We believe one of the more likely explanations to be the elevated oxygen cost of breathing. ${ }^{3-5,22}$ Such condition might be sustained by lung hyperinflation ${ }^{9,19}$ and loss in lung elastic recoil, ${ }^{23}$ causing an unfavorable length-tension relationship in the respiratory muscles.

Christensen and colleagues ${ }^{8}$ have recently tried to correlate changes in body weight with respiratory functional indices. They showed that weight gain was not correlated significantly with either improvement in lung mechanics or decrease in lung volumes, whereas it was correlated with improvement in gas exchanges, as measured by diffusing capacity. Engelen and associates ${ }^{24}$ showed that the best predictor of FFM depletion in patients with COPD in stable condition is the diffusing capacity. Furthermore, in a recent article Nezu and coworkers ${ }^{25}$ demonstrated that bilateral RP results in FFM gain in underweight patients, and they explained this as the result of an increment in tissue oxygen delivery related to reduction in breathing workload.

According to our findings, only RP was capable of improving nutritional status, as proved by significant changes in body composition and biochemical markers (Table 3) despite the substantial stability of energy intake and diet habits. No correlation was evident between nutritional markers and functional, exercise, and subjective indicators (Table 4). No significant changes in energy intake and diet composition were found before and after treatment, thus supporting the theory of an increased energy cost in patients with emphysematous, hyperinflated lungs, who can regain weight after RP.
To our knowledge this is the first randomized controlled study, to investigate the relative impacts of RP and RR on body weight and nutritional status. However, the strict selection criteria, difficulty in randomization acceptance, and the crossover design probably limit the sample size available for long-term follow-up. One further limit might be represented by the heterogeneity of the RP group, which included patients treated by unilateral and bilateral procedures. We did perform intentional unilateral and bilateral $\mathrm{RP}$ according to precise radiologic morphologic criteria for emphysema. ${ }^{15}$ The fact that we found no significant differences in weight gain when comparing the results achieved with unilateral and bilateral RP is consistent with our belief that both procedures have precise elective indications.

Patients with malnutrition related to emphysema were able to gain body weight after undergoing RP, mainly as a result of FFM increment, and to improve nutritional status within 6 months after the surgery, whereas no change was detectable in patients who had RR alone. Weight gain in patients after RP was linearly correlated with reduction of RV. Further investigation with more detailed metabolic assessment entailing basal and dynamic calorimetric measurements may give us much better insight into the complex interactions that result in weight loss and malnutrition in patients with emphysema.

We thank Simona Servetti, MD, for help in editing this article.

\section{References}

1. Congleton J. The pulmonary cachexia syndrome: aspects of energy balance. Proc Nutr Soc. 1999;58:321-8.

2. Wouters EF. Nutrition and metabolism in COPD. Chest. $2000 ; 117(5$ Suppl 1):274S-80S.

3. Schols AM, Soeters PB, Mostert R, Wouters EF. Energy balance in chronic obstructive pulmonary disease. Am Rev Respir Dis. 1991;143: 1248-52.

4. Donahoe M, Rogers RM, Wilson DO, Pennock BE. Oxygen consumption of the respiratory muscles in normal and in malnourished patients with chronic obstructive pulmonary disease. Am Rev Respir Dis. 1989;140:385-91. 
5. Hugli O, Schutz Y, Fitting JW. The daily energy expenditure in stable chronic obstructive pulmonary disease. Am J Respir Crit Care Med. 1996;153:294-300.

6. Baarends EM, Schols AM, Pannemans DL, Westerterp KR, Wouters EF. Total free energy expenditure in patients with severe chronic obstructive pulmonary disease. Am J Respir Crit Care Med. 1997;155: 549-54.

7. Cooper JD, Patterson GA. Lung-volume reduction surgery for severe emphysema. Chest Surg Clin North Am. 1995;5:815-31.

8. Christensen PJ, Paine R 3rd, Curtis JL, Kazerooni EA, Iannettoni MD, Martinez FJ. Weight gain after lung volume reduction surgery is not correlated with improvement in pulmonary mechanics. Chest. 1999; 116:1601-7.

9. Criner GJ, Cordova FC, Leyenson V, Roy B, Travaline JM, Sudarshan $\mathrm{S}$, et al. Effect of lung volume reduction surgery on diaphragm strength. Am J Respir Crit Care Med. 1998;157:1578-85.

10. Pompeo E, Marino M, Nofroni I, Matteucci G, Mineo TC. Reduction pneumoplasty versus respiratory rehabilitation in severe emphysema: a prospective randomized study. Ann Thorac Surg. 2000;70:948-53.

11. Task Group on Screening for Respiratory Disease in Occupational Setting. Official Statement of the American Thoracic Society. Am Rev Respir Dis. 1982;126:952-6.

12. Mahler DA, Mackowiak JI. Evaluation of the short-form 36-item questionnaire to measure health-related quality of life in patients with COPD. Chest. 1995;107:1585-9.

13. Durnin JV, Rahaman MM. The assessment of the amount of fat in the human body from measurement of skinfold thickness. $\mathrm{Br} \mathrm{J} \mathrm{Nutr}$. 1967;21:681-9.

14. Bishop CW, Bowen PE, Richey SJ. Norms for nutritional assessment of American adults by upper arm anthropometry. Am J Clin Nutr. 1981;34:2530-9

15. Pompeo E, Sergiacomi G, Nofroni I, Roscetti W, Simonetti G, Mineo TC. Morphologic grading of emphysema is useful in the selection of candidates for unilateral or bilateral reduction pneumoplasty. Eur J Cardiothorac Surg. 2000;17:680-6.

16. Criner GJ, Cordova FC, Furukawa S, Kuzma AM, Travaline JM, Leyenson V, et al. Prospective randomized trial comparing bilateral lung volume reduction surgery to pulmonary rehabilitation in severe chronic obstructive pulmonary disease. Am J Respir Crit Care Med. 1999;160:2018-27.

17. Geddes D, Davies M, Koyama H, Hansell D, Pastorino U, Pepper J, et al. Effect of lung-volume-reduction surgery in patients with severe emphysema. N Engl J Med. 2000;343:239-45.

18. O'Donnell DE, Webb KA, Bertley JC, Chau LK, Conlan AA. Mechanisms of relief of exertional breathlessness following unilateral bullectomy and lung volume reduction surgery in emphysema. Chest. 1996;110:18-27

19. O'Donnell DE, McGuire M, Samis L, Webb KA. General exercise training improves ventilatory and peripheral muscle strength and endurance in chronic airflow limitation. Am J Respir Crit Care Med. 1998;157:1489-97.

20. Mazolewski P, Turner JF, Baker M, Kurtz T, Little AG. The impact of nutritional status on the outcome of lung volume reduction surgery: a prospective study. Chest. 1999;116:693-6.
21. Creutzberg EC, Schols AM, Weling-Scheepers CA, Buurman WA, Wouters EF. Characterization of nonresponse to high caloric oral nutritional therapy in depleted patients with chronic obstructive pulmonary disease. Am J Respir Crit Care Med. 2000;161:745-52.

22. Jounieaux V, Mayeux I. Oxygen cost of breathing in patients with emphysema or chronic bronchitis in acute respiratory failure. Am J Respir Crit Care Med. 1995;152:2181-4.

23. Sciurba FC, Rogers RM, Keenan RJ, Slivka WA, Gorcsan J, Ferson $\mathrm{PF}$, et al. Improvement in pulmonary function and elastic recoil after lung-reduction surgery for diffuse emphysema. N Engl J Med. 1996; 334:1095-9.

24. Engelen MP, Schols AM, Baken WC, Wesseling JG, Wouters EF. Nutritional depletion in relation to respiratory and peripheral muscle function in outpatients with COPD. Eur Respir J. 1994;7:1793-7.

25. Nezu K, Yoshikawa M, Yoneda T, Kushibe K, Kawaguchi T, Yasukawa $\mathrm{M}$, et al. The change in body composition after bilateral lung volume reduction surgery for underweight patients with severe emphysema. Lung. 2000;178:381-9.

\section{Appendix}

\section{Pulmonary Emphysema Research Group (PERG) Clinical Centers}

Università Tor Vergata, Rome, Italy: Tommaso Claudio Mineo (principal investigator and coordinator), Eugenio Pompeo, Vincenzo Ambrogi, and Benedetto Cristino, Chirurgia Toracica; Alessandro Fabrizio Sabato and Mario Dauri, Anestesia e Rianimazione; GianLuigi Sergiacomi, Radiologia; Cesare Saltini, Paolo Rossi, and Lucia Senis, Pneumologia; Andrea Fabbri and Davide Mineo, Endocrinologia

Ospedale "Cartoni" Rocca Priora, Italy: Mario Marino, Giuseppe Matteucci, and Filippo DePadova

Dept. Medicina Sperimentale e Patologia Università "La Sapienza," Rome, Italy: Italo Nofroni

Istituto Nazionale della Nutrizione, Rome, Italy: Angela Polito

Ospedale S. Eugenio, Rome, Italy: Mauro Polzoni and Franco Turani, Anestesia e Rianimazione; Gaetano Aiello and Paola Codato, Fisiopatologia Respiratoria; Nello Giovannone and Gianpaolo Giovannone, Dietologia; Luca Piantoni, Endocrinologia; Cesidio Cipriani and Sergio Boemi, Medicina Nucleare

Ospedale Civile di Frascati, Italy: Luigi Casella.

Ospedale "S. Giuseppe" Marino: Franz Finocchio Thorel

Ospedale “Calai,” Gualdo Tadino, Italy: Marcello Paci

Ospedale Civile di Agnone, Italy: Nicola Iavicoli

Ospedale Civile di Lecce, Italy: Corrado Sorrenti and Gaetano Greco 